\title{
Three Configurations of Compact Planar Multistub Microstrip Antennas for mmW Mobile Applications
}

\author{
Asma Lak $\mathbb{D}^{1},{ }^{1}$ Zahra Adelpour $\mathbb{D}^{1},{ }^{1}$ Homayoon Oraizi, ${ }^{2}$ and Naser Parhizgar ${ }^{1}$ \\ ${ }^{1}$ Department of Electrical Engineering, Shiraz Branch, Islamic Azad University, Shiraz, Iran \\ ${ }^{2}$ School of Electrical Engineering, Iran University of Science and Technology, Tehran, Iran \\ Correspondence should be addressed to Zahra Adelpour; adelpour@aut.ac.ir
}

Received 18 September 2020; Revised 19 December 2020; Accepted 1 January 2021; Published 16 January 2021

Academic Editor: Paolo Burghignoli

Copyright (c) 2021 Asma Lak et al. This is an open access article distributed under the Creative Commons Attribution License, which permits unrestricted use, distribution, and reproduction in any medium, provided the original work is properly cited.

Three configurations of compact planar multistub antennas are proposed in the frequency range of $27-29.5 \mathrm{GHz}$ as candidates for the $5 \mathrm{G}$ standard frequency band. Each antenna consists of the same feeding part configuration but different structures for the dipole, director, and reflector parts. The feeding part is based on the substrate integrated waveguide (SIW) technology which results in compact size. The $\mathrm{TE}_{10}$ dominant mode is considered in the design procedure by HFSS software simulations. The proposed antennas have been simulated, fabricated, and measured (for $\mathrm{S}_{11}, E$, and $H$ pattern). The simulation and measurement results show reasonable agreement for $\mathrm{S}_{11}$ and radiation patterns of $\mathrm{E}$ - and $\mathrm{H}$-planes and impedance bandwidths. Moreover, for specific absorption rate (SAR) estimation, a three-layer human head model (skin, skull, and brain) is placed next to the antennas as the exposure source. The simulation results show the performance of the proposed antennas for low-SAR, which make them good candidates for safe usage concerning the negative impact of millimeter waves (mmWs) on human health. Finally, a comparison table is presented which verifies the compact size of our proposed antennas.

\section{Introduction}

Nowadays, the research on $5 \mathrm{G}$ mobile devices and systems has greatly expanded. The standards of these systems will take effect in 2020. One of the requirements of this generation of communication systems is the higher data rates due to the user's demands (such as high quality video chats and big volume file transmissions). The frequency spectrum below $6 \mathrm{GHz}$ has been used heavily for the increase in transmission rates. However, there is not enough space for the future developments in transmission rates because the $5 \mathrm{G}$ cellular systems and devices have to move to the higher frequency bands for high capacity and speed rates. Some frequency bands have been assigned as candidates for these networks, such as $27-29.5 \mathrm{GHz}$ and $40-50 \mathrm{GHz}$ bands $[1,2]$. Because of the available fabrication technologies, the $27-29.5 \mathrm{GHz}$ band is selected in our work. The users are generally concerned with the high frequency generation of radio waves because of the possibilities of health hazards. Generally, such effects are divided into two categories: thermal and nonthermal. The biological effects of electromagnetic fields have been reported so far, such as blood brain barrier, effects on the immune system, genetic effects, cancer aggravation, cataracts, and sleep disorder [3-8].

In the high frequency bands (e.g., $28 \mathrm{GHz}$ ), the waves cannot penetrate deeply into the human tissues due to the skin effect. Consequently, the thermal effect is dominant. The Federal Communication Commission (FCC) and International Commission on Nonionizing Radiation Protection (ICNIRP) have published the standards for the specific absorption rate (SAR) limitations for the frequencies lower than $6 \mathrm{GHz}$ and $10 \mathrm{GHz}$. At the frequencies above $10 \mathrm{GHz}$, the power density is used as the criterion, but it only describes the power travelling towards the tissue and not the absorbed power and the field distribution in the tissues [2]. SAR is a unit that evaluates the field distribution and absorption in the human body under the electromagnetic source exposure and depends on many parameters, such as human tissue geometry, source structure, frequency, time duration of exposure, and exposure environment [7]. 
There are several antenna structures introduced for 5G systems, such as Vivaldi, Fermi, log-periodic, quasi-Yagi, substrate integrated waveguide (SIW) cavity backed, and slot antennas [9-12]. However, our proposed configuration is based on quasi-Yagi travelling wave end-fire antenna, which consists of dipole elements, directors, reflectors, and feeding part. The director is a little shorter than the dipole, and the reflector is slightly longer. The gain of an array antenna depends on the number of elements. The parasitic elements absorb and reradiate the radio waves from the driven element with different phases, modifying the dipole's radiation pattern.

The reduction of transmission line length and radiation losses can be obtained by a simplified feeding system [13]. Recently, the SIW technology has been used in the antenna structures. Also the half-mode SIW (HMSIW) is an alternative method to reduce the size of antenna without degrading its performance. They can also be used in the travelling wave antennas [14]. The SIW technology needs high quality workmanship and possesses compact structure and small mass. Free space losses increase with frequency according to the Friis equation. In order to overcome this problem at high frequencies, the antenna gain has to be increased. The $5 \mathrm{G}$ systems promise wider range of users and applications but require low insertion losses, shorter delay, wider coverage, better connectivity, higher capacity, lower cost, and higher reliability. The $\mathrm{mmW}$ spectrum is an ideal candidate for the satisfaction of such demands.

In this paper, three compact planar end-fire antennas based on SIW technology have been designed in the band of 27-29.5 GHz. The design procedure, simulation, fabrication, and measurement results, together with SAR calculations are presented in the following sections. According to the obtained results, acceptable consistency between simulation results and measurement data is observed. According to the low calculated SAR values and compact size of the proposed antennas, they can be considered as good candidates for $5 \mathrm{G}$ mobile devices.

\section{Antenna Design}

2.1. Feeding Part. SIW technology is used to design the feeding network of antennas due to its several benefits, such as compact structure, low loss, and cost effectiveness. Figure 1 shows the feed-network which is the same for all the three proposed antennas. According to Figure $1,(w)$ is the width of waveguide, $w_{t}$ is the width of taper, $l_{t}$ is the length of taper, Ls is the length of SIW part, $s$ is the distance between two adjacent vias, and $d$ is the diameter of via. The antenna substrate is Roger RT/duroid 5880 with $\varepsilon_{r}=2.2$ and $h_{s u b}=0.38 \mathrm{~mm}$. The phase difference between the up and down plane is $180^{\circ}$. The $50 \Omega$ lumped port is used for the port excitation.

Based on the antenna feed system in Figure 1, the $\mathrm{TE}_{10}$ mode is excited and the physical parameters of the feeding part are calculated as follows which are almost equal for all the three antennas: $\mathrm{Ls}=3.5 \mathrm{~mm}$, wt $=3.2 \mathrm{~mm}, L=3.5 \mathrm{~mm}$,
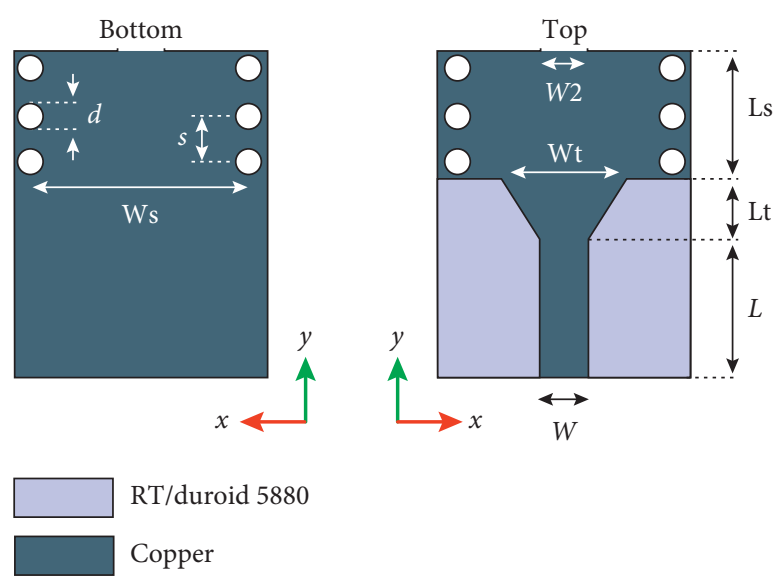

FIGURE 1: The feeding configuration of the proposed antennas.

$w 1=1.2 \mathrm{~mm}, \quad w=5.5 \mathrm{~mm}, \mathrm{Lt}=1.6 \mathrm{~mm}, d=0.6 \mathrm{~mm}$, and $s=0.6 \mathrm{~mm}$.

2.2. Antenna 1 Design. Antenna 1 is designed using the guidelines of [1] by some variations of the lengths and widths to operate in the frequency band $27-29.5 \mathrm{GHz}$ with specified gain and $S_{11}$. Figure 2 shows the structure of antenna 1 . The proposed antenna has a dipole, a spur line, and also an open stub for impedance matching, which can be tuned by its size and position. The lengths of the long and short designed dipoles generate the lower and upper modes. To increase the gain, one director is added to the structure. The calculated dimensions of the antenna according to Figure 2 are $L_{1}=2.5 \mathrm{~mm}, L_{2}=5 \mathrm{~mm} \quad L_{3}=1.615 \mathrm{~mm}, L_{4}=2.275 \mathrm{~mm}$, $L_{5}=1.25 \mathrm{~mm}, L_{6}=1.125 \mathrm{~mm}, W_{1}=0.4 \mathrm{~mm}, W_{2}=1.2 \mathrm{~mm}$, $W_{3}=0.5 \mathrm{~mm}, \quad W_{4}=0.75 \mathrm{~mm}, \quad W_{5}=0.5 \mathrm{~mm}, \quad$ and $W_{6}=0.5 \mathrm{~mm}$. Figure 3 shows the simulation results of $E$ and $H$ field patterns and $S_{11}$ of antenna 1 .

2.3. Antenna 2 Design. For antenna 2, the design rules of the log periodic antenna are used with the same feeding network. For the log-periodic antenna, the lengths $(L)$ and widths $(w)$ of adjacent elements are calculated by using the following $[15,16]$ :

$$
\tau=\left(\frac{L_{m+1}}{L_{m}}\right)=\left(\frac{W_{m+1}}{W_{m}}\right) .
$$

The design relations for antenna 2 according to [16] are as follows:

$$
\begin{aligned}
& \varepsilon_{\text {eff }}=\left(\frac{\varepsilon_{r}+1}{2}\right)+\frac{\left(\left(\varepsilon_{r}-1\right)\right)}{2}\left(1+12\left(\frac{h}{w}\right)^{-0.5}\right), \\
& L_{1}=\left(\frac{\lambda_{\text {effmax }}}{4}\right)=\left(\frac{c}{4}\right) \sqrt{\varepsilon_{\text {eff }}} f_{\text {min }},
\end{aligned}
$$

where $\lambda_{\text {eff }}$ is the effective wavelength, $h$ is the thickness of substrate, and $w$ is the width of the longest element. The number of elements $(N)$ is determined as follows: 

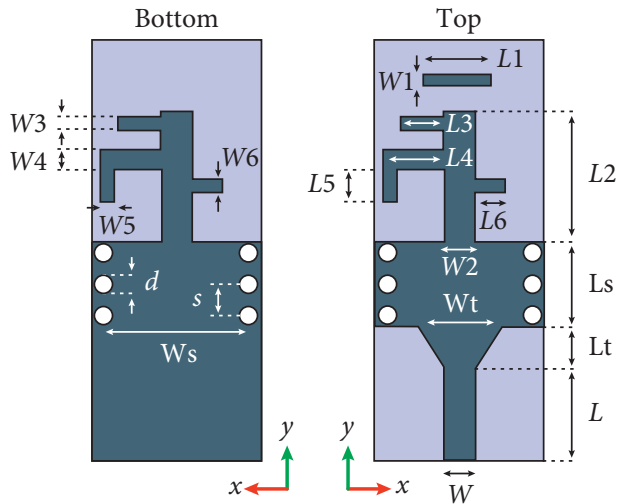

$\mathrm{RT} /$ duroid 5880

Copper

Figure 2: The structure of the proposed antenna 1.

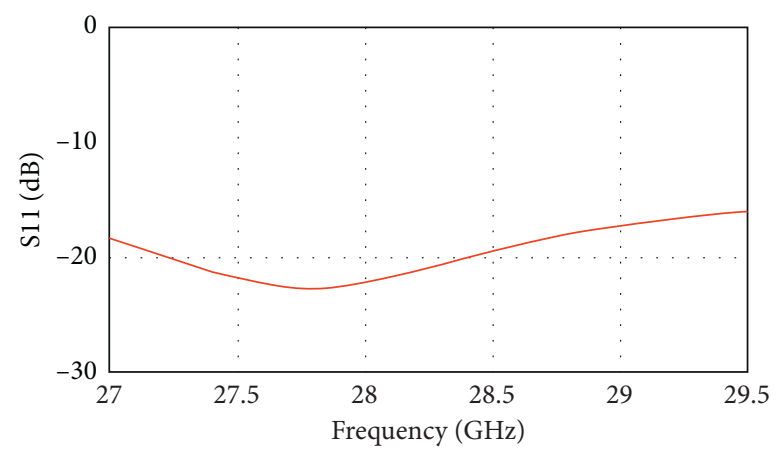

(a)

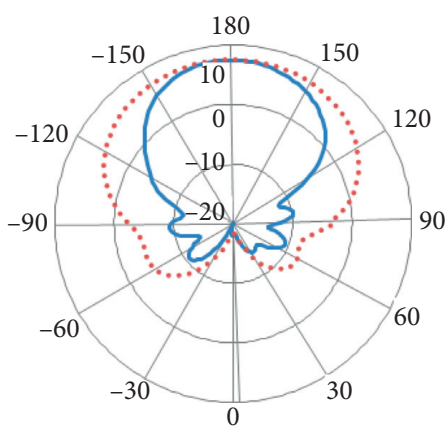

- E pattern

(b)

Figure 3: Simulation results of antenna 1: (a) $\mathrm{S}_{11}$ and (b) the $E$ and $H$ pattern.

$$
\begin{aligned}
\sigma & =\left(\frac{(1-\tau)}{4 \tan \alpha}\right), \\
N & =1+\left(\frac{\ln \left(B_{A R} \times B\right)}{\ln (1 / \tau)}\right), \\
B & =\left(\frac{f_{\text {max }}}{f_{\text {min }}}\right), \\
B_{\mathrm{AR}} & =1.1+7.7(1-\tau)^{2} \cot \alpha,
\end{aligned}
$$

where $\sigma$ is the spacing factor, $\alpha$ is the apex angle, $\tau$ is the geometry constant, and $B_{\mathrm{AR}}$ is the bandwidth of the active region. Assuming $7 \mathrm{~dB}$ gain, the values of $\tau=0.75$ and $\sigma=$ 0.131 are calculated. So, the number of elements is $N=3$. Figure 4 shows the structure of antenna 2.

According to Figure 4, the calculated dimensions are $L_{1}=2.8 \mathrm{~mm}, L_{2}=4.22 \mathrm{~mm} L_{3}=1.068 \mathrm{~mm}, L_{4}=1.425 \mathrm{~mm}$, $L_{5}=1.9 \mathrm{~mm}, W_{1}=0.75 \mathrm{~mm}, W_{2}=1.25 \mathrm{~mm}, W_{3}=0.14 \mathrm{~mm}$, $W_{4}=0.1875 \mathrm{~mm}$, and $W_{5}=0.25 \mathrm{~mm}$. The $E$ and $H$ field patterns and $S_{11}$ of antenna 2 are shown in Figure 5.

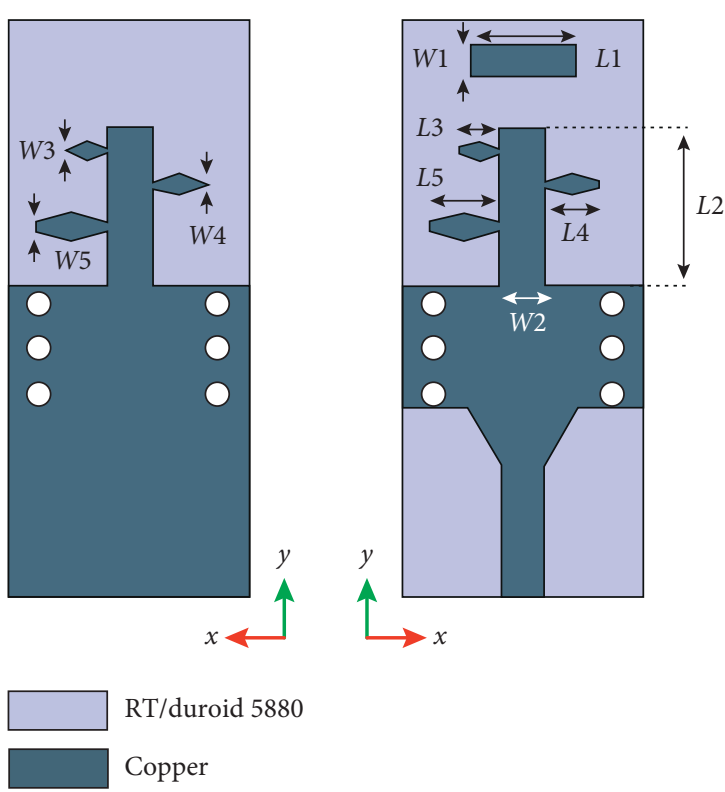

FIGURE 4: The structure of the proposed antenna 2. 


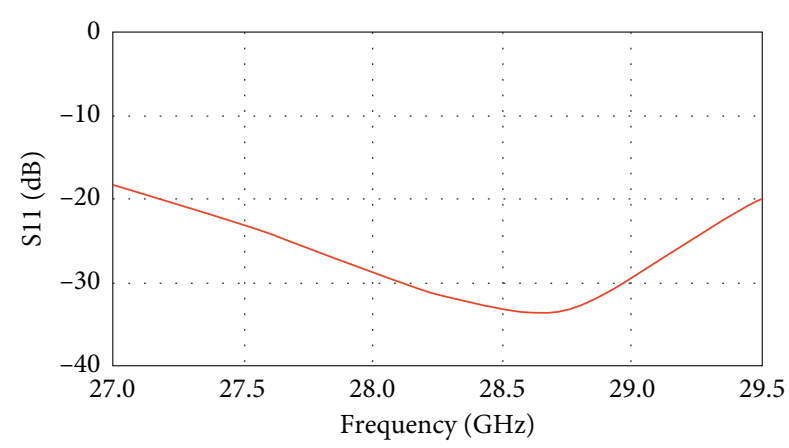

(a)

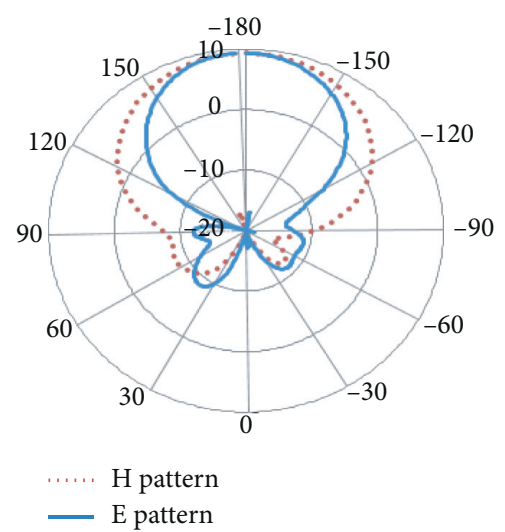

(b)

FIGURE 5: Simulation results of antenna 2: (a) $S_{11}$ and (b) the $E$ and $H$ pattern.

2.4. Antenna 3 Design. For antenna 3, according to [17], the lengths of the driver and director should be set as follows:

$$
\begin{gathered}
0.45 \lambda_{\text {eff }}<L_{3}<0.49 \lambda_{\text {eff }}, \\
0.4 \lambda_{\text {eff }}<L_{1}<0.45 \lambda_{\text {eff }} .
\end{gathered}
$$

In [18], the dipoles have been angled to compact the size. Figure 6 shows the proposed antenna 3 with the calculated dimensions of the antenna as follows: $L_{1}=2.5 \mathrm{~mm}$, $L_{2}=3.9 \mathrm{~mm}, L_{3}=1.8 \mathrm{~mm}, W_{1}=0.5 \mathrm{~mm}, W_{2}=0.6 \mathrm{~mm}$, and $W_{3}=0.6 \mathrm{~mm}$.

The simulations show that the obtained gain is not as good as the case of one dipole pair. To improve the antenna gain, the number of dipoles is increased and a director pair is also added. The $E$ and $H$ field patterns and $S_{11}$ of antenna 3 are shown in Figure 7.

For a better comparison, the summary of simulation results is shown in Table 1. Considering the gain and return loss, it can be deduced that antenna 2 shows better performance due to its log-periodic structure.

\section{Measurement Results}

The fabricated prototypes of three proposed antennas are shown in Figure 8.

The comparisons of return losses for measurement and simulation results of all three configurations are shown in Figure 9. Considering the high frequency range of operation and effect of SMK port, the measurement results are all in the acceptable range, well below $-10 \mathrm{~dB}$.

The antenna $\mathrm{E}$ - and $\mathrm{H}$-plane radiation patterns are shown in Figure 10. The results exhibit acceptable responses for $5 \mathrm{G}$ system goals (namely, end-fire antenna patterns). The simulation and measurement results are in good agreement, which show that all antennas are applicable in the desired frequency band. Note that in this high frequency range, the calibration of lab equipment, temperature effects, and fabrication process faults is inevitable and can be considered as the reason for the differences between simulation and measurement results.

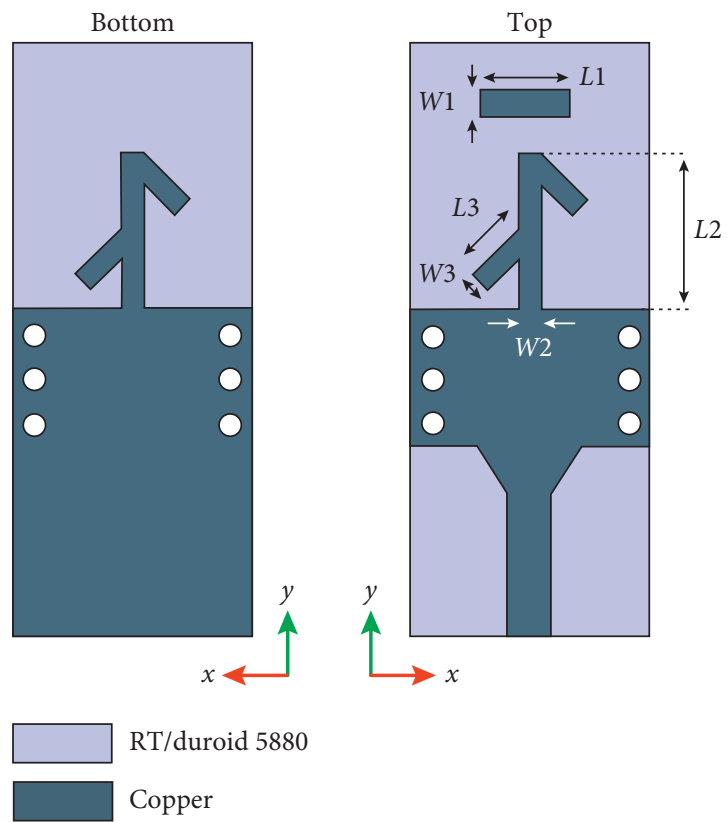

FIgURE 6: The structure of the proposed antenna 3.

The results show acceptable values for operation in the $28 \mathrm{GHz}$ frequency band and for hand-held devices like cell phones because of their small size, good gain, and $S_{11}$ coefficient.

Although the performances of all three proposed antennas are in the satisfactory range, antenna 2 shows better performance which can be associated with its dipole design and log-periodic design rules, by which the gain is predictable and can be estimated in advanced. Moreover, in this antenna type, the number of dipoles is more than the two other types.

Observe that the gain values of 7-9 dB obtained by our antenna designs are not sufficient for the $\mathrm{mmW}$ band, and it is suggested that they be used in array configurations for practical usage. 


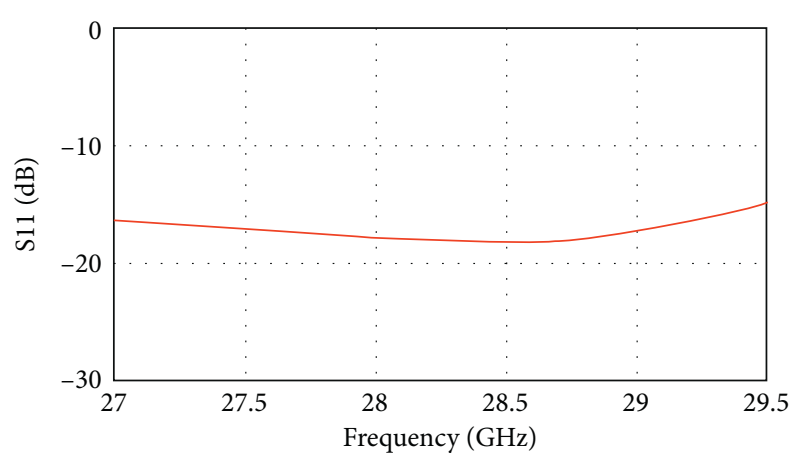

(a)

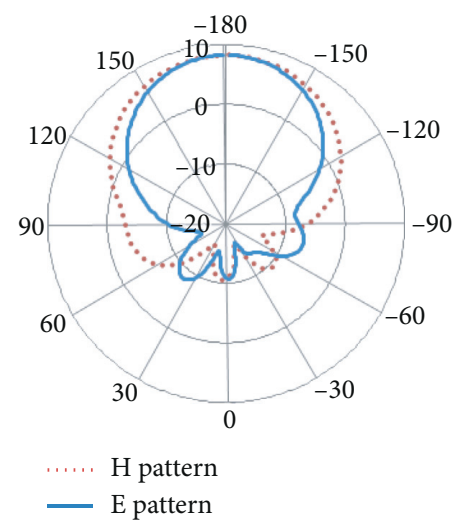

(b)

FIgURE 7: simulation results of antenna 3: (a) $S_{11}$ and (b) the $E$ and $H$ pattern.

TABLE 1: The simulation results of the proposed antennas.

\begin{tabular}{cccc}
\hline Parameter & Max gain $(\mathrm{dB})$ & S11 $(\mathrm{dB})$ & Size $\left(\mathrm{mm}^{3}\right)$ \\
\hline Antenna 1 & 7.53 & $<-15.92$ & $16 \times 6.5 \times 0.38$ \\
Antenna 2 & 9.34 & $<-18.27$ & $16 \times 6.5 \times 0.38$ \\
Antenna 3 & 8.24 & $<-14.8$ & $16 \times 6.5 \times 0.38$ \\
\hline
\end{tabular}

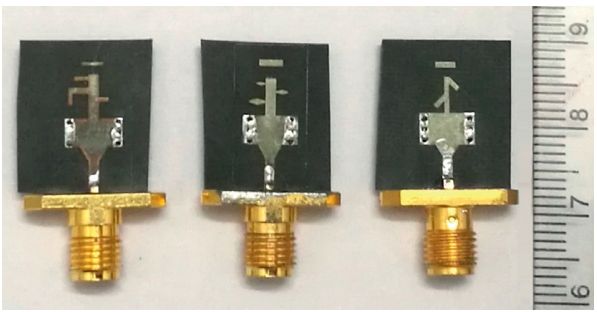

FIgURE 8: The fabricated prototypes of three proposed antennas.

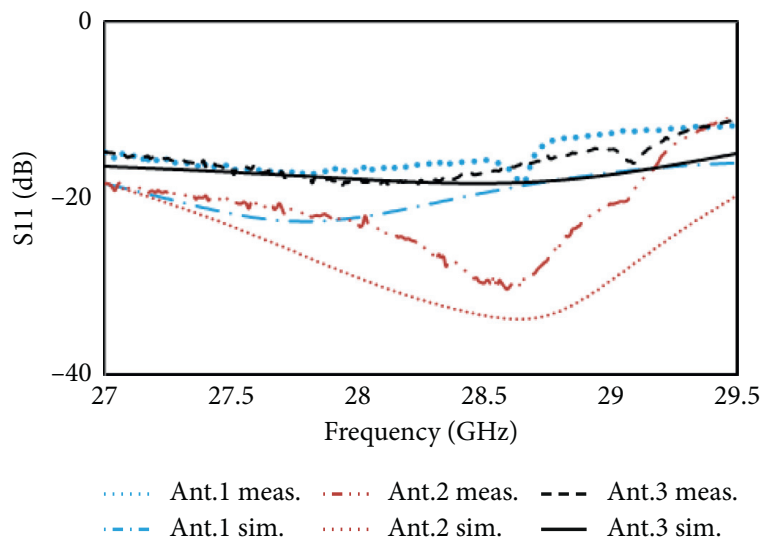

Figure 9: Reflection coefficient of three proposed antennas.

\section{Human Head Model and SAR Results}

Considering the objectives of array design for the practical application of the proposed antennas (namely, higher gain level needed to overcome the high losses in the $\mathrm{mmW}$ band), it is necessary to be sure about the performance of the single element for the SAR calculations. Thus, in the first stage,
SAR calculations for the single element are carried out, which can highly ensure its performance in the array structure.

4.1. Human Tissues Dielectric Properties. Considering the dielectric properties of biological tissues, they are obviously affected by the electromagnetic fields. The dielectric properties of tissues are conductivity $(\sigma)$, relative permittivity $\left(\varepsilon_{r}\right)$, and relative permeability $\left(\mu_{r}\right)$. They play a significant role in SAR evaluations while studying the propagation characteristic of $\mathrm{mmW}$. The attenuation, reflection, and propagation behavior of electromagnetic fields in the human body are determined by such properties. The dielectric properties of tissues are chosen according to [19]. These properties are dependent on frequency, geometry, size of tissue, and water contents. The dependency on frequency for a high water content tissue is shown in Figure 11.

The measurement of the electromagnetic field deposition in biological tissues (human body) is difficult and complex. Consequently, appropriate simulation and computational methods are suggested for the evaluation of electromagnetic wave propagation. Therefore, suitable phantoms as human body models have been designed in different shapes, such as cubic, bowl, sphere, and cylinder. The three-layer spherical head model used in our simulation is shown in Figure 12.

In the proposed model, the human head tissues are modeled as skin, skull, and brain. The dielectric characteristics of tissues at $28 \mathrm{GHz}$ are considered as follows:

$$
\begin{aligned}
& \text { Skin : } \varepsilon_{r}=18.71, \sigma=26.19, R_{\text {skin }}=106.5, \\
& \text { Skull : } \varepsilon_{r}=7.51, \sigma=8.88, R_{\text {skull }}=105.1 \mathrm{~mm}, \\
& \text { Brain : } \varepsilon_{r}=18.59, \sigma=21.86, R_{\text {brain }}=93.8 \mathrm{~mm} .
\end{aligned}
$$

The shell is a low-loss dielectric with $\varepsilon_{r}=4.5$, and $R$ is the radius of the spherical head model.

4.2. Specific Absorption Rate. Specific absorption rate (SAR) is a parameter to quantify the absorption of energy in tissues and is expressed in watts per unit mass of tissue $(W / \mathrm{kg})$. In other words, SAR is the time derivative of incremental 


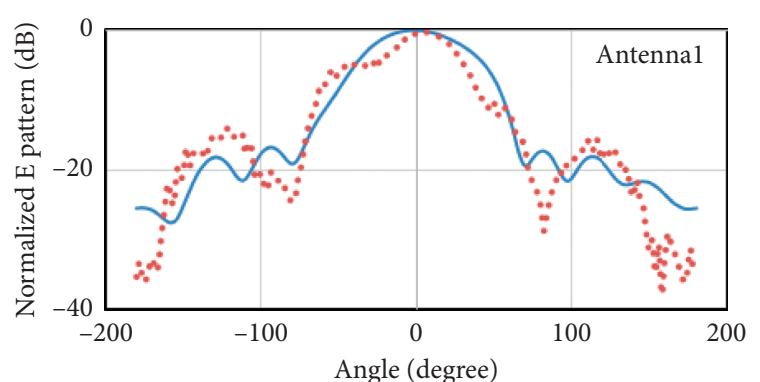

— Sim.

..... Maes.

(a)

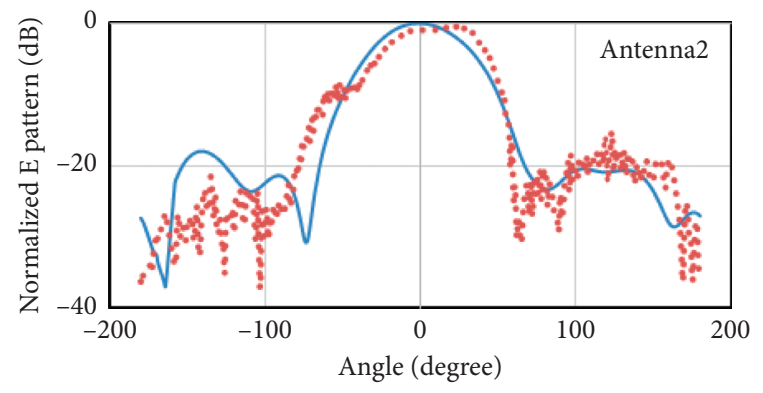

- Sim.

..... Maes.

(c)

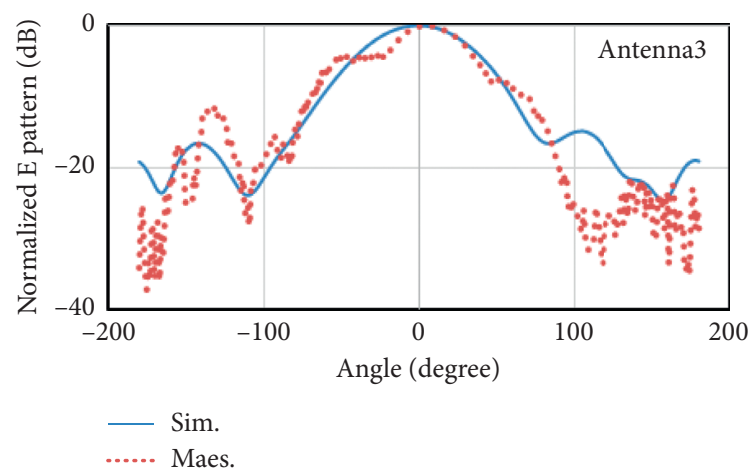

(e)

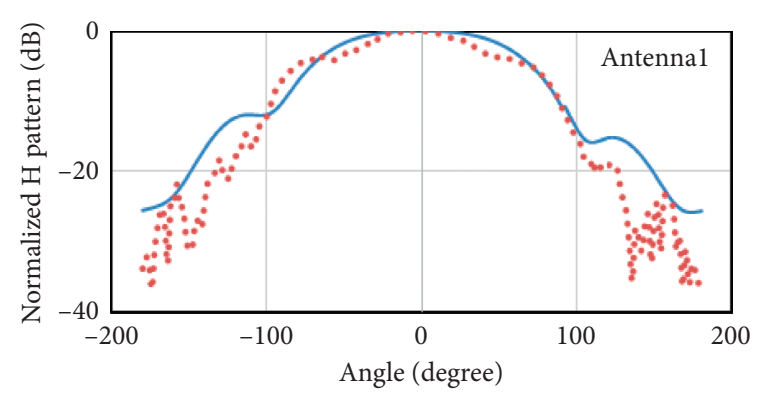

— Sim.

...... Maes.

(b)

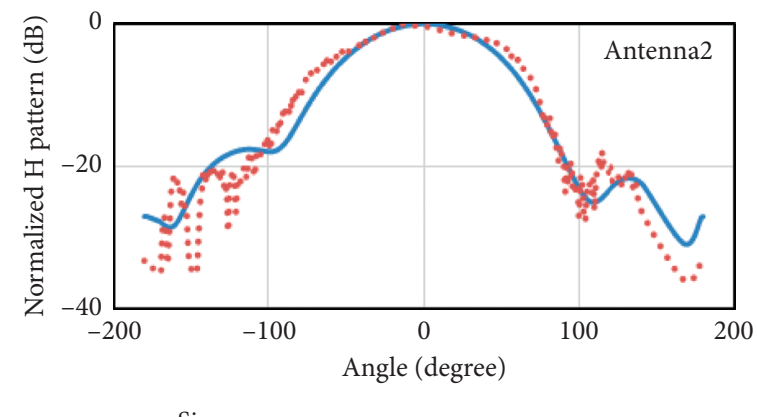

- Sim.

..... Maes.

(d)

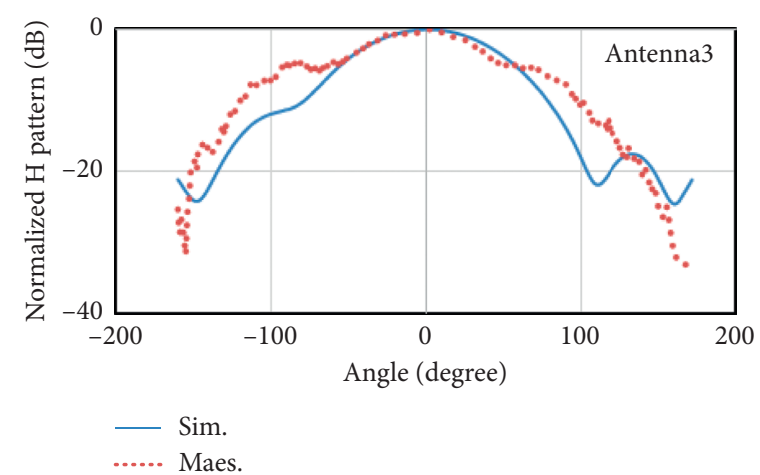

(f)

Figure 10: Normalized $\mathrm{H}$ and E patterns of the proposed antennas at $28 \mathrm{GHz}$. (a) and (b) antenna 1; (c) and (d) antenna 2; (e) and (f) antenna 3.

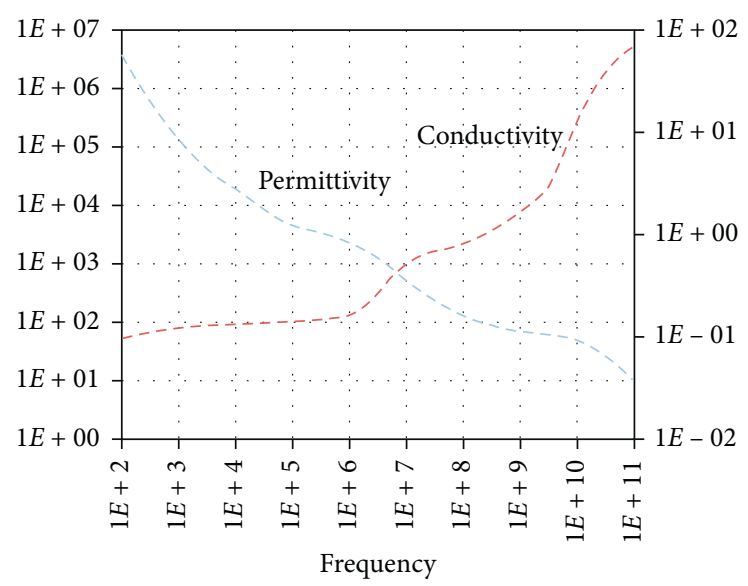

FIGURE 11: Dielectric properties of a high water content tissue [3]. 


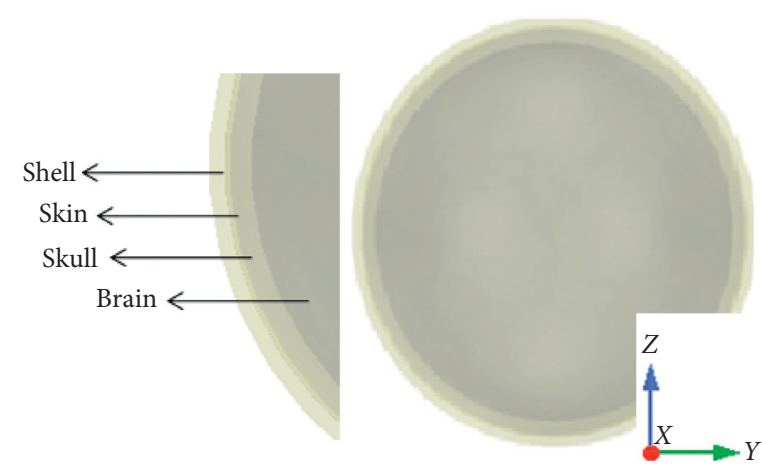

FIgURe 12: The three-layer human head model $[3,20]$.
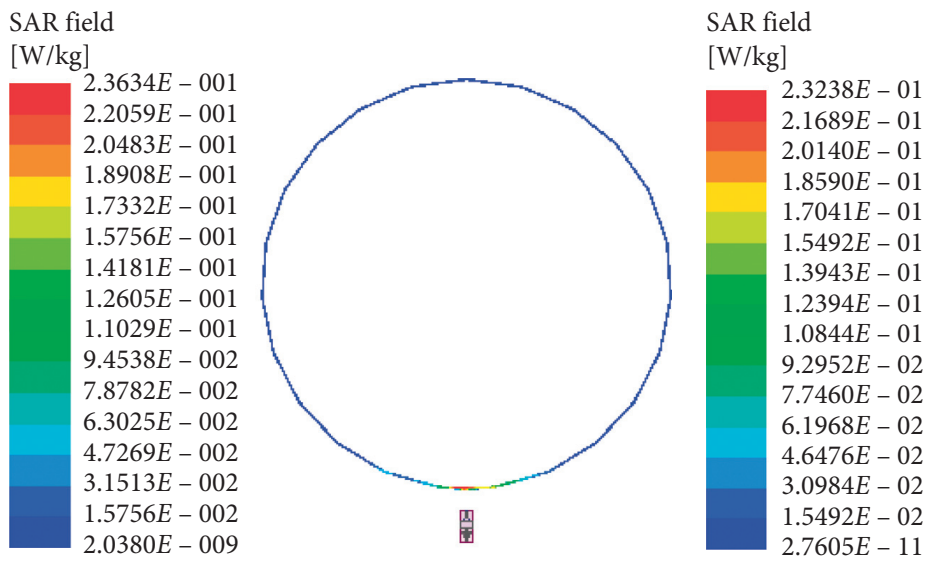

(a)

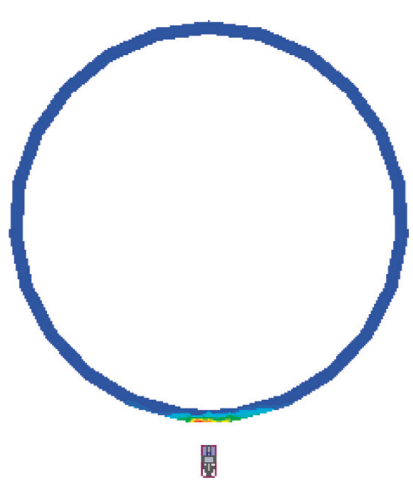

(b)

SAR field [W/kg]
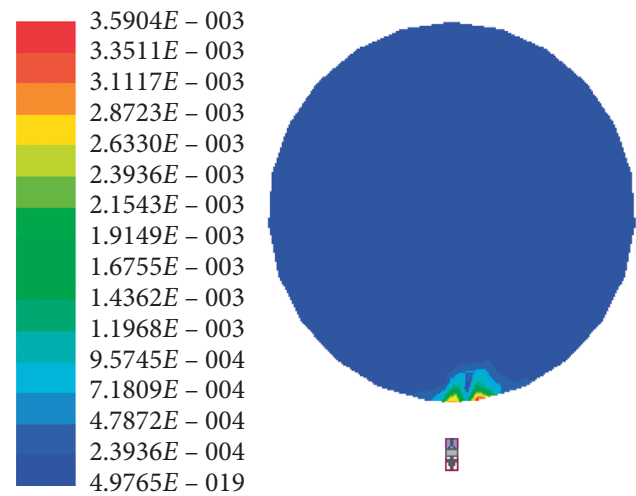

(c)

FIGURE 13: $\mathrm{SAR}_{1 \mathrm{~g}}$ measurements at $28 \mathrm{GHz}$ for $15 \mathrm{dBm}$ input power onto (a) skin, (b) skull, and (c) brain.

energy (dW) absorbed by an incremental mass (dm), defined as follows [20]:

$$
\mathrm{SAR}=\frac{d W}{d m}=\frac{d W}{\rho d v}\left(\frac{\mathrm{Watt}}{\mathrm{kg}}\right) .
$$

SAR is also defined as follows [21]:

$$
\mathrm{SAR}=\sigma \frac{E_{i}^{2}}{\rho}=\left(\sigma+\omega \varepsilon_{0} \varepsilon^{\prime \prime}\right) \frac{E_{i}^{2}}{\rho},
$$

where $\sigma$ is the conductivity of tissue, $E$ is the electric field intensity, $\rho$ is the mass density of tissue, $\omega$ is angular frequency, $\varepsilon^{\prime \prime}$ is the imaginary part dielectric constant, and $\varepsilon_{0}$ is the free space permittivity $[3,21]$. 
TABLE 2: The averaged $S_{1 g}$ and $S_{10}$ for $15 \mathrm{dBm}$ input power.

\begin{tabular}{llll}
\hline SAR $(\mathrm{W} / \mathrm{Kg})$ & Skin & Skull & Brain \\
\hline Antenna 1 (SAR1 g) & 0.236 & 0.232 & 0.0035 \\
Antenna 2 (SAR1 g) & 0.284 & 0.235 & 0.0044 \\
Antenna 3 (SAR1 g) & 0.416 & 0.37 & 0.0079 \\
Antenna 1 (SAR10 g) & 0.081 & 0.074 & 0.074 \\
Antenna 2 (SAR10 g) & 0.071 & 0.063 & 0.063 \\
Antenna 3 (SAR10 g) & 0.169 & 0.143 & 0.143 \\
\hline
\end{tabular}

TABLE 3: The averaged $\mathrm{SAR}_{1 \mathrm{~g}}$ and $\mathrm{SAR}_{10 \mathrm{~g}}$ for $20 \mathrm{dBm}$ input power.

\begin{tabular}{lccc}
\hline SAR(W/Kg) & Skin & Skull & Brain \\
\hline Antenna 1 (SAR1 g) & 0.747 & 0.734 & 0.011 \\
Antenna 2 (SAR1 g) & 0.9 & 0.746 & 0.013 \\
Antenna 3 (SAR1 g) & 1.32 & 1.17 & 0.002 \\
Antenna 1 (SAR10 g) & 0.256 & 0.234 & 0.234 \\
Antenna 2 (SAR10 g) & 0.237 & 0.20 & 0.20 \\
Antenna 3 (SAR10 g) & 0.536 & 0.453 & 0.453 \\
\hline
\end{tabular}

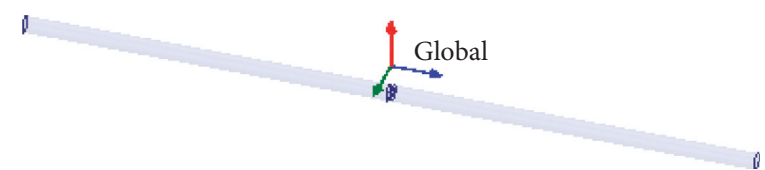

FIgURE 14: The dipole antenna at $28 \mathrm{GHz}$.

TABLE 4: The average $\mathrm{SAR}_{1 \mathrm{~g}}$ and $\mathrm{SAR}_{10 \mathrm{~g}}$ for the dipole antenna.

\begin{tabular}{lccc}
\hline SAR $(\mathrm{W} / \mathrm{Kg})$ & Skin & Skull & Brain \\
\hline SAR1 g $(15 \mathrm{dBm})$ & 1.81 & 1.85 & 0.013 \\
SAR10 $\mathrm{g}(15 \mathrm{dBm})$ & 0.51 & 0.56 & 0.56 \\
SAR1 g $(20 \mathrm{dBm})$ & 5.73 & 5.86 & 0.043 \\
SAR10 $\mathrm{g}(20 \mathrm{dBm})$ & 1.62 & 1.76 & 1.76 \\
\hline
\end{tabular}

In the real SAR measurement system, one robot arm measures the $E$ or $H$ field by using an electric probe at various positions of the model and a computer processor calculates the SAR value. The distance between the antenna and head model, according to the literatures, can be set to $5 \mathrm{~mm}, 10 \mathrm{~mm}, 15 \mathrm{~mm}$, or even $20 \mathrm{~mm} \mathrm{[2,3,20,22].} \mathrm{SAR} \mathrm{is}$ usually averaged over a small volume of tissue (1 Gram or 10 Gram of tissue) named as $\mathrm{SAR}_{1 \mathrm{~g}}$ and $\mathrm{SAR}_{10}$. It has been shown that by increasing the distance, SAR value decreases [3]. According to FCC standards, the input powers of $15 \mathrm{dBm}$ and $20 \mathrm{dBm}$ are reported for SAR calculations $[20,22]$.

Each of the three proposed antennas as the exposure source is placed at the distance of $5 \mathrm{~mm}$ from the head model for the assessment and calculation of the SAR by using HFSS software. Because of the similarity of the obtained results, only the simulation results of antenna 1 with $15 \mathrm{dBm}$ input power are shown in Figure 13.

Tables 2 and 3 show the results of $S_{1 g}$ and $S A R_{10 g}$ which are low values and guarantee their save safety for the human health. Note that all three proposed antenna structures have end-fire radiation patterns which automatically result in SAR reduction. Also the results show that the skin tissue has the maximum SAR because it is the nearest tissue to the exposure source. As Tables 2 and 3 show, the proposed three antennas have good values for SAR. The brain tissue has the smallest values because it is the innermost and furthest away layer among the three parts.

To compare the obtained results with a dipole antenna (like the commercial SAR measurement system), a dipole antenna is designed at the frequency of $28 \mathrm{GHz}$ and placed at $5 \mathrm{~mm}$ distance of the human head model (Figure 14). Then, the SAR value is calculated. At the frequency of $28 \mathrm{GHz}$, the dipole length is equal to approximately $5 \mathrm{~mm}$. The radius of dipole arms is set to $3.6 \mathrm{~mm}$.

Obviously, it can be seen that the SAR values of our proposed antennas (Tables 2 and 3 ) are less than the values of dipole one (Table 4), which emphasize the health safety of the proposed antennas for the $5 \mathrm{G}$ system.

Several techniques can be used to reduce the SAR values, such as RF shields, reflectors, AMC and EBG structures, meta-material cells, and also highly directive antennas. The research in [23] has reported that the replacement of common antennas on mobile platforms by highly directive 
TABLE 5: Comparison of the proposed antenna with other references.

\begin{tabular}{|c|c|c|c|c|c|}
\hline & Antenna type & Substrate & $\mathrm{BW}(\mathrm{GHz})$ & Relative size $\left(\lambda_{0}^{3}\right)$ & Size reduction $(\%)$ \\
\hline$[24]$ & Quasi-Yagi-Uda & Rogers 4003 & $\begin{array}{l}30.7-43 \\
33.4-42\end{array}$ & $1.14 \times 1.03 \times 0.18$ & $84 \%$ \\
\hline [25] & Quasi-Yagi & Rogers 5880 & $26-30.1$ & $2.14 \times 1.87 \times 0.075$ & $89 \%$ \\
\hline [26] & 5G antenna based on the Franklin model & Rogers 5880 & $\begin{array}{c}27.9-33.2 \\
34-39.1\end{array}$ & $1.18 \times 2.8 \times 0.075$ & $86 \%$ \\
\hline [27] & $5 \mathrm{G}$ antenna & Rogers 5880 & $22.5-38.7$ & $0.71 \times 5.6 \times 0.147$ & $94 \%$ \\
\hline$[28]$ & Microstrip folded dipole antenna & GaAs & $34-37.5$ & $2.34 \times 2.34 \times 0.068$ & $91 \%$ \\
\hline Proposed antenna 1 & $\begin{array}{l}\text { Planar multistub } \\
\text { Microstrip }\end{array}$ & Rogers 5880 & $27-29.5$ & $0.61 \times 1.5 \times 0.036$ & - \\
\hline Proposed antenna 2 & $\begin{array}{c}\text { Planar multistub } \\
\text { Microstrip }\end{array}$ & Rogers 5880 & $27-29.5$ & $0.61 \times 1.5 \times 0.036$ & - \\
\hline Proposed antenna 3 & $\begin{array}{c}\text { Planar multistub } \\
\text { Microstrip }\end{array}$ & Rogers 5880 & $27-29.5$ & $0.61 \times 1.5 \times 0.036$ & - \\
\hline
\end{tabular}

antennas significantly reduces the EM energy radiated towards the human head. Consequently, the end-fire characteristics of the proposed antennas result in lower SAR values.

Finally, for a better demonstration of the benefits of proposed antennas, their obtained results are compared in Table 5 with those of other $5 \mathrm{G}$ antenna types reported in the recent literature. Observe that our proposed antennas have considerably smaller compact size which is an important factor for mobile devices. Moreover, the calculated SAR values in the previous section guarantee their performances for practical usage.

\section{Conclusion}

Three planar antennas with compact size $(6.5 \mathrm{~mm} \times 16 \mathrm{~mm} \times 0.38 \mathrm{~mm})$ on Roger RT/duroid 5880 substrate with end-fire radiation patterns are proposed, designed, fabricated, and measured. The feed system is identical for all the three antennas while their radiation elements are different. The application of substrate integrated waveguide technology for the proposed antennas to realize end-fire radiation patterns in a compact size leads to their low values of specific absorption rate. The simulation and measurement results of return loss and radiation patterns are presented which show good agreement. Two features of proposed antennas are compact size and low specific absorption rate value, which make them appropriate candidates for $5 \mathrm{G}$ mobile devices.

\section{Data Availability}

The data used to support the findings of this study are available from the corresponding author upon request.

\section{Conflicts of Interest}

The authors declare that they have no conflicts of interest.

\section{References}

[1] Y. W. Wang, H. Wang, and G. Yang, "Design of dipole beamsteering antenna array for 5G handset applications," in
Proceedings of the Progress in Electromagnetic Research Symposium (PIERS), Shanghai, China, August 2016.

[2] T. Hamed and M. Maqsood, "SAR calculation \& temperature response of human body exposure to electromagnetic radiations at 28, 40 and 60GHz mmWave frequencies," Progress in Electromagnetics Research M, vol. 73, pp. 47-59, 2018.

[3] A. Lak and H. Oraizi, "Evaluation of SAR distribution in six layer human head model," International Journal of Antennas and Propagation, vol. 2013, Article ID 580872, 8 pages, 2013.

[4] A. Lak, "Human health effects from radiofrequency and microwave fields," Journal of Basic and Applied Science Researches, vol. 2, no. 12, pp. 12302-12305, 2012.

[5] A. Lak and M. Lak, "SAR dependence on antenna position," Advance in environmental biology, vol. 8, 2014.

[6] A. Lak and N. Parhizgar, "The effect of presence of human body on antenna gain," Indian Journal of Science and Technology, vol. 8, 2015.

[7] A. Lak and H. Oraizi, "Simulation and evaluation of specific absorption rate in human bodyin high frequency electromagnetic fields," Advanced Materials Research Journal, vol. 433-440, Switzerland, 2012.

[8] F. Gustrau and A. Bahr, "W-band investigation of material parameters, SAR distribution, and thermal response in human tissue," IEEE Transactions on Microwave Theory and Techniques, vol. 50, no. 10, pp. 2393-2400, 2002.

[9] I. Mohamed, Z. Briqech, and A. Sebak, "Antipodal Fermi tapered slot antenna for $60-\mathrm{GHz}$ band Applications," IEEE Antennas and Wireless Propagation Letters, vol. 14, 2015.

[10] Q. X. Chu, "High gain printed log-periodic dipole array antenna with parasitic cell for $5 \mathrm{G}$ communication," IEEE Transactions on Antennas and Propagation, vol. 99, 2017.

[11] G. H. Zhai, W. Hong, K. Wu et al., "Printed quasi-yagi antenna fed by half mode substrate integrated waveguide," in Proceedings of the 2008 Asia-Pacific Microwave Conference, Hong Kong, China, December 2008.

[12] N. Ojaroudiparchin, M. Shen, and G. Frølund Pedersen, "Design of vivaldi antenna array with end-fire beam steering function for 5G mobile terminals," in Proceedings of the 23rd Telecommunications forum TELFOR, Belgrade, Serbia, November 2015.

[13] Y. F. Lin, C. H. Lin, H. M. Chen, and P. S. Hall, "A miniature dielectric loaded monopole antenna for $2.4 / 5 \mathrm{GHz}$ WLAN applications," IEEE Microwave and Wireless Components Letters, vol. 16, no. 11, 2006.

[14] Y. J. Cheng, Substrate Integrated Antenna and Arrays, Taylor \& Francis Group, Florida, USA, 2016. 
[15] O. M. Haraz, S. A. Alshebeili, and A.-R. Sebak, "Low- cost high gain printed log-periodic dipole array antenna with dielectric lenses for V-band applications," IET Microwaves, Antennas \& Propagation, vol. 9, no. 6, 2015.

[16] H. Oraizi, A. Amini, and M. KarimiMehr, "Design of miniaturized UWB log-periodic end-fire antenna using several fractals with WLAN band-rejection," IET Microwaves Antennas \& Propagation, vol. 11, 2019.

[17] Y. S. Amrullah, Y. N. Wijayanto, A. Setiawan, and Y. Wahyu, "Enhancement of Quasi Yagi antenna design for ka-band application," in Proceedings of the 2017 International Conference on Radar, Antenna Microwave, Electronics, and Telecomm-unications, Jakarta, Indonesia, May 2017.

[18] S. X. Ta and I. Park, "Broadband printed-dipole antennas for millimeter-wave applications," in Proceedings of the 2017 IEEE Radio and Wireless Symposium (RWS), Phoenix, ARI, USA, January 2017.

[19] C. Gabriel, S. Gabriel, and E. Corthout, "The dielectric properties of biological tissues: I. Literature survey," Physics in Medicine \& Biology, vol. 41, no. 11, pp. 2231-2249, 1996.

[20] W. He, B. Xu, M. Gustafsson, Z. Ying, and S. He, “"RF compliance study of temperature elevation in human head model around $28 \mathrm{GHz}$ for $5 \mathrm{G}$ user equipment application: simulation analysis", special section on resent advances on radio access and security methods in $5 \mathrm{G}$ networks," IEEE Access, vol. 6, 2017.

[21] M. Ibrani, L. Ahma, and E. Hamiti, "Comparative SAR assessment in adult and children exposed to electromagnetic fields of radio frequency device," WSEAS Transaction on communication, vol. 9, 2010.

[22] D. Colombi, B. Thors, and C. Törnevik, "Implications of EMF exposure limits on output power levels for $5 \mathrm{G}$ devices above 6 $\mathrm{GHz}$," IEEE Antennas and Wireless Propagation Letters, vol. 14, 2015.

[23] R. Pikale, D. Sangani, P. Chaturvedi, A. Soni, and M. Munde, "A review: methods to lower specific absorption rate for mobile phones," in Proceedings of the 2018 International Conference on Advances in Communication and Computing Technology, February 2018.

[24] Y. Hsu, T. C. Huang, H. S. Lin, and Y. C. Lin, "Dualpolarized quasi yagi-uda antennas with end-fire radiation for millimeter-wave MIMO terminals," IEEE Transactions on Antennas and Propagation, vol. 65, 2017.

[25] M. Nouri, S. A. Aghdam, A. Jafarieh, J. Bagby, and S. Sahebghalam, "A wideband millimeter-wave antenna based on Quasi-Yagi antenna with mimo circular array antenna beam forming for $5 \mathrm{G}$ wireless networks," Microwave and Optical Technology Letter, vol. 1, 2019.

[26] S. F. Jilani, Q. H. Abbasi, Z. U. Khan, T. H. Loh, and A. A. K. Alomainy, "A Ka-Band antenna based on an enhanced $\mathrm{f}$ ranklin model for $5 \mathrm{G}$ cellular networks," Microwave and Optical Technology Letters, vol. 16, 2018.

[27] J. Wang, Y. Li, L. Ge et al., "Millimeter-wave wideband circularly polarized planar complementary source antenna with end-fire radiation," IEEE Transaction on Antennas and Propagation, vol. 66, 2018.

[28] G. Hua, C. Yang, P. Lu, H.-X. Zhou, and W. Hong, "Microstrip folded dipole antenna for $35 \mathrm{GHz}$ MMW communication," International Journal of Antennas and Propagation, vol. 2013, Article ID 603654, 6 pages, 2013. 